\title{
Do secretions from the uropygial gland of birds attract biting midges and black flies?
}

Josué Martínez-de la Puente \& Juan Rivero-de Aguilar \&

Sara del Cerro \& Anastasio Argüello \& Santiago Merino

\begin{abstract}
Bird susceptibility to attacks by blood-sucking flying insects could be influenced by urogypial gland secretions. To determine the effect of these secretions on biting midges and black flies, we set up a series of tests. First, we placed uropygial gland secretions from blue tit Cyanistes caeruleus broods inside empty nest boxes while empty nest boxes without gland secretions were treated as controls. Blue tit broods, from which we had obtained uropygial secretions, were affected by biting midges and black flies. However, these insects were absent in nest boxes both with and without secretions from nestlings' uropygial glands. We subsequently tested for the effects of uropygial gland secretions from feral pigeons Columba livia monitoring the number of biting midges captured using miniature CDC traps. There was no significant difference in the number of biting midges captured. Overall, our results did not support a potential role of avian uropygial gland secretions in attracting biting midges and black flies.
\end{abstract}

J. Martínez-de la Puente • A. Argüello

Department of Animal Science,

Universidad de las Palmas de Gran Canaria,

Arucas, Spain

J. Rivero-de Aguilar $:$ S. del Cerro $:$ S. Merino

Departamento de Ecología Evolutiva,

Museo Nacional de Ciencias Naturales (CSIC),

Madrid, Spain

J. Martínez-de la Puente ( $\star$ ) Departamento

de Ecología de Humedales, Estación

Biológica de Doñana (EBD-CSIC),

C/Americo Vespucio, s/n,

41092 Seville, Spain

e-mail: jmp@ebd.csic.es
Introduction

Host seeking is a complex behaviour developed by blood-sucking insects to locate their hosts and satisfy their nutritional requirements. Insects may use different cues including odours or metabolic products (i.e. carbon dioxide, octenol and lactic acid), visual stimuli and temperature to detect hosts (Gibson and Torr 1999; Lehane 2005). For ornithophilic blood-sucking flying insects, volatile components from feathers or the skin or other avian-derived products, including faeces, also play a role in attracting insects (Lowther and Wood 1964; Fallis and Smith 1964; Allan et al. 2006; Cooperband et al. 2008; Syed and Leal 2009). In particular, secretions from the uropygial gland (also called preen gland), commonly used by birds for feather maintenance, may affect the interaction between insects and avian species (Lowther and Wood 1964; Fallis and Smith 1964; Bennett et al. 1972; Russell and Hunter 2005).

In cavity-nesting species, adults suffer from attacks of blood-sucking flying insects (e.g. mosquitoes, biting midges and black flies) during incubation and brooding, with nestlings also suffering these attacks until fledging (Tomás et al. 2008b; Ligon et al. 2009; Martínez-de la Puente et al. 2009a). These insects produce adverse effects on birds, including the transmission of blood parasites and tissue damage, affecting health status and survival probability (Smith et al. 1998; Tomás et al. 2008a; Martínez-de la Puente et al. 2010). Weather conditions and host-related factors such as brood size, infection status and host species determine the number of blood-sucking flying insects in avian nests (Tomás et al. 2008a; Martínez-de la Puente et al. 2009b, c). However, further studies are necessary to reveal the role of host odours affecting bird-blood-sucking flying insect interactions under natural conditions. We conducted 
two experiments in different areas using two different bird species to test whether the secretions from the uropygial gland have a role in attracting blood-sucking flying insects. The species used were blue tits Cyanistes caeruleus and feral pigeons Columba livia. First, we studied the impact of secretions from the uropygial gland of blue tit nestlings on the number of biting midges and black flies in nest boxes. Subsequently, we studied the influence of uropygial gland secretions from feral pigeons on biting midge and black fly captures using miniature Centre for Disease Control (CDC) traps. The feral pigeon is a bird species commonly seen perching on fences and other structures in the study area but not occupying nest boxes.

\section{Methods}

\section{Experiment 1}

This study was conducted during the spring of 2010 in a population of blue tits $\mathrm{C}$. caeruleus breeding in nest boxes in a Pyrenean oak Quercus pyrenaica forest (Central Spain, $40^{\circ} 53^{\prime} 74 \mathrm{~N}, 4^{\circ} 01^{\prime} \mathrm{W}, 1,200 \mathrm{~m}$ a.s.l.). Wooden nest boxes were hung from branches about $4 \mathrm{~m}$ above the ground. When nestlings were 10 days old, we placed a plastic Petri dish $\left(10 \times 4 \mathrm{~cm} ; 40 \mathrm{~cm}^{2}\right)$ with a thinly spread layer of body gel oil (Johnson's baby chamomilla; Johnson \& Johnson, Dusseldorf) inside the nesting box, close to the roof, to capture flying insects (see Tomás et al. 2008b). The gel oil comprised paraffinum liquidum, hexyl laurate, ethylene/ propylene/styrene copolymer, cyclopentasiloxane, butylene/ ethylene/styrene copolymer, Chamomilla recutita, bisabolol and fragrance (FPT1353). Three days later, Petri dishes were removed from the nest boxes. At that moment, uropygial gland secretions were obtained from each nestling of the same brood, pushing the opening of the papilla with microtubes. Secretions from the uropygial gland were obtained from broods containing an average of 8.6 ( \pm 1.6$)$ nestlings. The secretions obtained from all nestlings of the same brood were all pooled and subsequently deposited in cotton dishes by transferring the content from the microtubes (approximately $25 \mu \mathrm{l}$ ). Each cotton dish, impregnated with uropygial secretions, was transported inside a Petri dish to reduce potential evaporation and immediately deposited in an empty nest box. A cotton dish without uropygial secretions was put inside another empty nest box (control nest). A total of 14 nest boxes, seven with uropygial gland secretions and seven control nest boxes, were included in this experiment. Each pair of nest boxes (a control nest and a nest box with secretions) was hung up on branches of the same tree. The distance between nest boxes was approximately $3 \mathrm{~m}$. The same method described above was used to capture blood- sucking flying insects for 2 days. The number of biting midges and black flies collected in Petri dishes was quantified under binocular lens (Motic K700; ×46.5 magnification).

\section{Experiment 2}

This experiment was conducted between 21 July 2010 and 14 September 2010 in the farm of the University of Las Palmas de Gran Canaria (Arucas, Canary Isles, $28^{\circ} 8^{\prime} 21 \mathrm{~N}$, $15^{\circ} 30^{\prime} 24 \mathrm{~W}$ ). For ten nights, between 7 p.m. and 8 a.m., we captured insects using two CDC-type downdraft miniature suction traps supplied with a 4-W blacklight (UV) bulb (model 1212; J.W.Hock, Gainesville, FL). Each night, a cotton swab impregnated with $15 \mu \mathrm{l}$ from a pool of uropygial gland secretions from feral pigeons C. livia was attached close to the fan entrance of one trap (see Russell and Hunter 2005). For this purpose, secretions from uropygial glands obtained from pigeons captured in the same area had been stored in Eppendorf tubes at $-20^{\circ} \mathrm{C}$ until use. An additional CDC trap (control trap) was located $21 \mathrm{~m}$ away from the trap with uropygial gland secretions. A cotton swab without avian secretions was attached close to the fan intake of the control trap. Both traps were hung at $2.20 \mathrm{~m}$ above ground level and were operating with UV light. Although the efficacy of the method could vary between species, UV light traps are considered convenient and useful surveillance tools for biting midge capture (Bishop et al. 2006; Gerry et al. 2009). The numbers of biting midge females collected were compared between traps with treated and non-treated cotton swabs.

Statistical analyses were conducted by using nonparametric tests (Statistica version 6.0, StatSoft, 2001). Wilcoxon matched pairs test for comparing two dependent variables (a non-parametric statistic) was used to test for differences in the numbers of insects captured in traps with and without (control) uropygial gland secretions. Means are shown with standard deviation.

\section{Results}

\section{Experiment 1}

Secretions from the uropygial gland were obtained from seven broods. All nests containing live birds were affected by biting midges and black flies. A total of 234 biting midges (average, 33.4 \pm 29.3 ; range, 8-94) and 182 black flies (average, 26.0 \pm 22.6 ; range, 4-63) were collected during the 3-day period of capture in nests containing nestlings. In contrast, biting midges and black flies were both absent in control nest boxes and nest boxes with uropygial gland secretions during the 2-day period of insect capture. 
Experiment 2

A total of 129 female biting midges were captured using two miniature CDC traps operating during ten nights. An average of $5.3( \pm 6.3$; range, $0-20)$ and 7.6 ( \pm 6.6 ; range, $0-$ 20) biting midges were captured in traps with avian secretions and control traps, respectively. The treatment did not significantly affect biting midge captures using miniature CDC traps $(\mathrm{Z}=1.13, \mathrm{p}=0.26)$. No black flies were captured.

\section{Discussion}

Overall, our results did not support a potential role of avian uropygial gland secretions as being attractive to biting midges and black flies. In contrast, secretions from the uropygial gland had formerly been shown to affect the interaction between birds and ectoparasites including feather mites and lice (Galván and Sanz 2006; Møller et al. 2010). However, contrary to the case of blood-sucking flying insects, feather mites and lice are permanent ectoparasites inhabiting the feather surface. A potential effect of uropygial secretions on blood-sucking flying insects could be the release of odours potentially used to locate their hosts. Host-seeking behaviour by blood-sucking dipterans includes different phases and cues used by the dipterans may differ with respect to the distance between the insects and their potential hosts (Gibson and Torr 1999). Moreover, although a particular cue could attract insects, the combination of several derived stimuli could be more attractive to insects. Supporting this possibility, the ornithophilic Simulium euryadminiculum, which is highly attracted to extracts from uropygial glands (Fallis and Smith 1964), showed higher responses in the presence of both carbon dioxide and avian extracts than one stimulus alone, indicating a synergistic effect (Bennett et al. 1972). Moreover, Allan et al. (2006) found stronger mosquito attraction by the combined use of feathers and carbon dioxide than by using each component alone, although the strongest responses were obtained in the presence of a Leghorn hen. These results suggest that other cues only emitted by living hosts may be used by blood-sucking insects to locate their feeding resources. This could be the reason for the absence of blood-sucking flying insects in nest boxes with avian secretions although the birds from which we obtained these secretions attracted both biting midges and black flies. Supporting the need of living birds to attract flying biting insects is the fact that nest boxes with previously used nests attract almost no blood-sucking flying insects (Tomás et al. 2008b), although avian faeces and feathers still present in those nests could potentially attract insects (Allan et al. 2006; Cooperband et al. 2008).
Different cues not modified in our study could also play a key role in insect attraction. In addition to carbon dioxide, which is considered a common attractant for blood-sucking insects, host temperature could affect the number of bloodsucking flying insects in nests (Kline and Lemire 1995; Martínez-de la Puente et al. 2010).

In the second experiment, the addition of secretions from the uropygial gland did not significantly affect the number of biting midges captured using miniature CDC traps. Some black fly and mosquito species are attracted to secretions from the uropygial gland (Bennett et al. 1972; Russell and Hunter 2005). However, in the case of Lutzomyia longipalpis, for example, a species commonly found in the field congregating around chicken coops, uropygial gland extracts did not increase insect captures (Nigam and Ward 1991). Recently, Russell and Hunter (2005), who used a similar procedure to that employed here, found a significant effect of avian odours on insect captures in traps placed at a height of $5 \mathrm{~m}$, but not at a height of $1.5 \mathrm{~m}$. We placed traps at a height of $2.20 \mathrm{~m}$, so it is possible that differences in the numbers of biting midges relative to height could affect our results. However, this could not explain the absence of blood-sucking flying insects in nest boxes from blue tits in the first experiment because these nest boxes were situated at similar heights than those containing nestlings and where insects were captured. Other methodological differences could also explain discrepancies between our results from experiment 2 and those from Russell and Hunter (2005) including the light source, the origin of secretions or the insect species studied. With one exception (an unidentified Culicoides specimen), the biting midges captured in experiment 2 were identified as members belonging to the Culicoides obsoletus complex. The morphological characters are not reliable enough to identify to species level females of the C. obsoletus complex. However, (a) in the Canary Isles, where we conducted the experiment 2, only C. obsoletus and Culicoides analis have been found (Delécolle 2002), (b) only C. obsoletus males have been captured in the study area (authors personal observations) and (c) biting midge species belonging to the "obsoletus complex" including C. obsoletus and Culicoides scoticus, trapped near livestock farms, are capable of feeding on birds such as mallards and common wood pigeons (Lassen et al. 2010). Therefore, although the biting midges were not attracted by bird secretions but by the UV light, this is not because pigeons are not potential hosts for these species.

In conclusion, we did not find support for an attractant effect of secretions from the uropygial gland alone to biting midges and black flies. However, these secretions in combination with other bird-related factors, such as nest temperature or emitted metabolic products, could well affect the abundance of biting midges and black flies in avian nests. 
Acknowledgements Financial support was provided by projects CGL2009-09439 and AGL 2009-11944 from Ministerio de Ciencia e Innovación. Junta de Castilla y León authorized the ringing and handling of birds in Valsaín. We also extend our gratitude to Javier Donés (Director of "Montes de Valsaín") for permission to work in Valsaín. Excmo. Ayuntamiento de Arucas authorized the handling of pigeons. J.M.P. was supported by a postdoctoral grant from the Universidad de Las Palmas de Gran Canaria. We thank N. Castro, I. Moreno, A. Morales and L. Hernández for their help. An anonymous reviewer and A P. Møller considerably improved a previous version of the manuscript. We specially thank Heather Briggs for checking the English. This study is a contribution to the research partially developed at "El Ventorrillo" field station.

\section{References}

Allan SA, Bernier UR, Kline DL (2006) Laboratory evaluation of avian odors for mosquito (Diptera: Culicidae) attraction. J Med Entomol 43:225-231

Bennett GF, Fallis AM, Campbell AG (1972) The response of Simulium (Eusimulium) euryadminiculum (Davies) (Diptera: Simuliidae) to some olfactory and visual stimuli. Can J Zool 50:793-800

Bishop AL, Bellis GA, McKenzie HJ, Spohr LJ, Worrall RJ, Harris AM, Melville L (2006) Light trapping of biting midges Culicoides spp. (Diptera: Ceratopogonidae) with green lightemitting diodes. Aust J Entomol 45:202-205

Cooperband MF, McElfresh JS, Millar JG, Carde RT (2008) Attraction of female Culex quinquefasciatus Say (Diptera: Culicidae) to odors from chicken feces. J Insect Physiol 54:1184-1192

Delécolle JC (2002) Ceratopogonidae. In: Carles-Tolrá Hjorth-Andersen M (ed) Catálogo de los Diptera de España, Portugal y Andorra (Insecta). Monografías S.E.A. 8:26-33

Fallis AM, Smith SM (1964) Ether extracts from birds and $\mathrm{CO}_{2}$ as attractants for some ornithophilic simuliids. Can J Zool 42:723730

Galván I, Sanz JJ (2006) Feather mite abundance increases with uropygial gland size and plumage yellowness in great tits Parus major. Ibis 148:687-697

Gerry AC, Sarto I, Monteys V, Moreno Vidal J-O, Francino O, Mullens BA (2009) Biting rates of Culicoides midges (Diptera: Ceratopogonidae) on sheep in northeastern Spain in relation to midge capture using UV light and carbon dioxide-baited traps. J Med Entomol 46:615-624

Gibson G, Torr SJ (1999) Visual and olfactory responses of haematophagous Diptera to host stimuli. Med Vet Entomol $13: 2-23$

Kline DL, Lemire GF (1995) Field evaluation of heat as an added attractant to traps baited with carbon dioxide and octenol for Aedes taeniorhynchus. J Am Mosq Control Assoc 11:454-456
Lassen SB, Nielsen SA, Skovgård H, Kristensen M (2010) Molecular identification of bloodmeals from biting midges (Diptera: Ceratopogonidae: Culicoides Latreille) in Denmark. Parasitol Res 108:823-829

Lehane M (2005) The biology of blood-sucking in insects, 2nd edn. Cambridge University Press, Cambridge

Ligon RA, Burkett-Cadena ND, Liu M, Hill GE, Hassan KH, Unnasch TR (2009) Assessing mosquito feeding patterns on nestling and brooding adult birds using microsatellite markers. Am J Trop Med Hyg 81:534-537

Lowther JK, Wood DM (1964) Specificity of a black fly, Simulium euryadminiculum Davies, toward its host, the common loon. Can Entomol 96:911-913

Martínez-de la Puente J, Merino S, Lobato E, Rivero-de Aguilar J, del Cerro S, Ruiz-de-Castañeda R (2009a) Testing the use of a citronella-based repellent as an effective method to reduce the prevalence and abundance of biting flies in avian nests. Parasitol Res 104:1233-1236

Martínez-de la Puente J, Merino S, Lobato E, Rivero-de Aguilar J, del Cerro S, Ruiz-de-Castañeda R, Moreno J (2009b) Does weather affect biting fly abundance in avian nests? J Avian Biol 40:653657

Martínez-de la Puente J, Merino S, Tomás G, Moreno J, Morales J, Lobato E, Talavera S, Sarto i Monteys V (2009c) Factors affecting Culicoides species composition and abundance in avian nests. Parasitology 136:1033-1041

Martínez-de la Puente J, Merino S, Lobato E, Rivero-de Aguilar J, del Cerro S, Ruiz-de-Castañeda R, Moreno J (2010) Nest-climatic factors affect the abundance of biting flies and their effects on nestling condition. Acta Oecol 36:543-547

Møller AP, Erritzøe J, Rózsa L (2010) Ectoparasites, uropygial glands and hatching success in birds. Oecologia 163:303-311

Nigam Y, Ward RD (1991) The effect of male sandfly pheromone and host factors as attractants for female Lutzomyia longipalpis (Diptera: Psychodidae). Physiol Entomol 16:305-312

Russell CB, Hunter FF (2005) Attraction of Culex pipiens/restuans (Diptera: Culicidae) mosquitoes to bird uropygial gland odors at two elevations in the Niagara region of Ontario. J Med Entomol 42:301-305

Smith RN, Cain SL, Anderson SH, Dunk JR, Williams S (1998) Blackfly-induced mortality of nestling red-tailed hawks. Auk 115:368-375

Syed Z, Leal WS (2009) Acute olfactory response of Culex mosquitoes to a human- and bird-derived attractant. Proc Natl Acad Sci USA 106:18803-18808

Tomás G, Merino S, Martínez-de la Puente J, Moreno J, Morales J, Lobato E (2008a) Determinants of abundance and effects of blood-sucking flying insects in the nest of a hole-nesting bird. Oecologia 156:305-312

Tomás G, Merino S, Martínez-de la Puente J, Moreno J, Morales J, Lobato E (2008b) A simple trapping method to estimate abundances of blood-sucking flying insects in avian nests. Anim Behav 75:723-729 